\title{
RESEARCH PAPER \\ A statistical approach for assessing the heterogeneity of Hass avocados subjected to different postharvest abiotic stresses
}

\author{
Claudia Fuentealba ${ }^{1}$, Romina Pedreschi ${ }^{1}$, Ignacia Hernández ${ }^{1}$, and Jorge \\ Saavedra ${ }^{2}$
}

${ }^{1}$ Pontificia Universidad Católica de Valparaíso, Facultad de Ciencias Agronómicas y de los Alimentos, Escuela de Agronomía. San Francisco s/n, La Palma, Quillota, Chile.

${ }^{2}$ Pontificia Universidad Católica de Valparaíso, Facultad de Ciencias Agronómicas y de los alimentos, Escuela de Alimentos, DataChem AgroFood Group. Waddington 716, Playa Ancha, Valparaíso, Chile.

\begin{abstract}
C. Fuentealba, R. Pedreschi, I. Hernández, and J. Saavedra. 2016. A statistical approach for assessing the heterogeneity of Hass avocados subjected to different postharvest abiotic stresses. Cien. Inv. Agr. 43(3):356-365. Hass avocado (Persea americana Mill.) is marketed worldwide. Due to its complex physiology, a wide variability in postharvest ripening can be observed, i.e., heterogeneity in the number of days to reach edible ripeness. There is a need for a simple and objective method for evaluating the efficacy of postharvest treatments in the reduction of this postharvest ripening heterogeneity given the high demand of import countries for consistent quality and product homogeneity. Therefore, the aim of this study was to compare the appropriateness of different statistical methods used to evaluate this ripening heterogeneity. Bartlett's, Cochran's, Levene's homogeneity of variance tests were applied to different treatments. In addition, a multiple comparisons test of squared residuals (parametric and non-parametric) was applied. The classical statistical approaches (Bartlett's, Cochran's and Levene's tests) showed similar results as the multiple comparisons test of squared residuals only when one treatment and large sample sizes $(n=100)$ were evaluated. All statistical methods were able to detect significant differences in ripening heterogeneity from growers and storage conditions. The multiple comparisons test of squared residuals was the most suitable method for multifactorial experiments and small sample sizes $(\mathrm{n}=30)$ compared to the classical approaches, which increased the probability of obtaining false positives or a type I error.
\end{abstract}

Key words: Avocados, heterogeneity, multiple comparison, ripening, standard deviation.

\section{Introduction}

Hass is the main avocado cultivar commercialized worldwide. The extended flowering time, very

Received Febreary 25, 2016. Accepted October 15, 2016. Corresponding author: claudia.fuentealba@pucv.cl low percentage of fruit set and inability to ripen on the tree renders the product heterogeneous (Lewis, 1978; Woolf et al., 2004). The variable postharvest ripening of this fruit creates severe logistical problems for marketers and inconsistent quality delivery to consumers given the high demand of the product in the ready-to-eat stage (Blakey et al., 2009). 
Several pre-harvest factors such as environmental conditions, cultural practices and endogenous systems of fruit growth are involved in this avocado postharvest ripening heterogeneity (Woolf et al., 2000; Woolf and Ferguson, 2000; Blakey et al., 2009; Hershkovitz et al., 2009). Regarding the post-harvest factors, several treatments have been applied (Bill et al., 2014), but focus has mainly been placed on the average time to reach edible ripeness rather than on reducing the spread of avocado ripening within a batch. Low temperature storage is the most commonly used method for extending the postharvest life of avocado (Bower and Cutting, 1988). Thus, an avocado fruit ripened at lower temperatures $\left(15-18^{\circ} \mathrm{C}\right)$ takes longer to ripen than those ripened at $20^{\circ} \mathrm{C}$ (Hofman et al., 2003; Arpaia and Obenland, 2012). In addition, cold and hot temperature treatments have been studied, where hot water treatment shortens the ripening period, improves color development and reduces external chilling injury, improving external and internal fruit quality (Hofman et al., 2002; Blakey and Bower, 2007), and in-orchard chilling stress causes an induction of avocado ripening through ethylene biosynthesis (Hershkovitz et al., 2009). Blakey and Bower (2007) evaluated the spread of avocado ripening as the number of days to the maximum number of ripe fruits starting once the first fruit was ripened; they concluded that the hot water treatment reduced the spread of ripening compared to a control without treatment. In addition, Blakey et al. (2009) reported that water infusion through the stem decreased the ripening heterogeneity, and abscisic acid accelerated the ripening process with no effect on the spread of the number of days to reach edible ripeness. Nevertheless, those conclusions were generated from small designed experiments (based on 10 fruits), and the conclusions generated from both experiments were not based on a statistical analysis. Recently, Pedreschi et al. (2014) used a much higher number of samples at harvest $(\mathrm{n}=100)$, classified fruit ranging from fast ripening to never ripening and demonstrated that the content of $\mathrm{C}_{7}$ sugars (mannoheptulose and perseitol), total fruit calcium and dry matter at harvest were not correlated with the observed differences in ripening speed. A further metabolomics analysis elucidated the content differences in certain amino acids and fatty acids that correlated with the observed ripening heterogeneity.

Kruger and Volschenk (2011) studied the ripening patterns of Hass fruit retained at three packing houses, determining the mean number of days required to ripen each sample. They also calculated the mean standard deviation as an indicator of the ripening spread or variation, and the statistical significance was determined by means of a Student's T test. In a similar manner, Kruger and Magwaza (2012) evaluated the effect of the soil moisture content on ripening as the number of days to ripening and compared the standard deviations. The main disadvantages of comparing standard deviations with a Student's T test are the limitation of comparing more than two treatments and the use of average standard deviations; in some cases, especially when the data are non-normally distributed, the spread may be better represented by medians (Mason et al., 2003).

Thus, there is need for an objective and simple method to assess the degree of heterogeneity of Hass avocado batches subjected to different post-harvest abiotic stresses in order to search for practical solutions for reducing this fruit industry problem. These methods would be able to evaluate and discriminate different sources of variability. The variability could be measured in different ways, i.e., standard deviations, ranges or variances. The commonly used methods include: Bartlett's test, Levene's test and Cochran's test, among others (Mason et al., 2003; Milliken and Johnson, 2009; Rykov et al., 2010). They are mainly based on comparing variances within a treatment to an average variance (Milliken and Johnson, 2009). However, those statistical approaches offer a global decision of the data using an estimated statistic contrasted with a reference statistic proposed by particular methods (Montgomery, 2008). In this way, the obtained information is reduced to whether the variability is different. 
The Hartley's FMAX test, which compares the standard deviations of two populations, is not a suitable option for comparing detailed variability of several populations because it is very sensitive to non-normal and non-independent distributions (Mason et al., 2003). Ferrer and Romero (1993) proposed a relatively simple principle of variability comparison, the Iterated Weighted Least Squares Procedure (IWLS), to evaluate the dispersion effects. IWLS is an iterative procedure that estimates by ordinary least squares (OLS) regression of $\log \left(e_{j}^{2}\right)$, where $e_{j}$ represents the estimated residuals in the weighted least squares regression of the response variable. The method consists of replacing the response variable in each experiment by the square of the residuals, which is a good estimator of the variability (asymptotically unbiased and small variance), and comparing it through multiple-comparison methods such as Tukey-HSD or Fisher-LSD (Carroll and Ruppert, 1988; Mason et al., 2003; Montgomery, 2008).

The aim of this study was to compare different statistical approaches used to evaluate the postharvest ripening heterogeneity of different Hass avocado batches submitted to different postharvest management operations. Relying on statistics to assure the appropriateness of postharvest treatments to reduce the ripening spread of Hass avocado batches is a useful and solid approach for practical implementations, and it will help the industry reduce the logistical problems associated with postharvest ripening heterogeneity.

\section{Materials and methods}

\section{Fruit material and treatments}

Avocados (Persea americana Mill. cv Hass) were sourced from different growers from the Region of Valparaiso, Chile. The fruit were immediately transported to the laboratory facilities at Instituto de Investigaciones Agropecuarias (INIA) and cooled to $5{ }^{\circ} \mathrm{C}$ overnight.
The data from three different experiments were evaluated, and all experiments were independent. Experiment 1 included a total of 460 early season Hass avocados (23-26\% dry matter) from 4 different growers collected and labelled as A, B, C, and D. The fruit was ripened at $20{ }^{\circ} \mathrm{C}$ and $60-70 \%$ relative humidity $(\mathrm{RH})$, and the ready-to-eat stage (RTE) or edible ripeness, expressed as days, was reached at a fruit firmness of 4.4-13.3 $\mathrm{N}$ for each individual fruit. Experiment 2 included a total of 300 middle season Hass avocados (26-30\% dry matter). One third of the fruit was maintained at $5{ }^{\circ} \mathrm{C}$ and $90-95 \% \mathrm{RH}$ for 30 days in regular air (RA), another third was subjected to commercially controlled atmospheric (CA) conditions $\left(4 \% \mathrm{O}_{2}\right.$ and $6 \% \mathrm{CO}_{2}$ at $5^{\circ} \mathrm{C}$ and $90-95 \% \mathrm{RH}$ ) for 30 days and the remaining third was used as the control group (ripened at harvest). The fruit was ripened at $20^{\circ} \mathrm{C}$ and $60-70 \% \mathrm{RH}$, and the RTE (days) was recorded for each individual fruit as mentioned for the previous experiment. Experiment 3 included a total of 720 middle season Hass avocados (26-30\% dry matter) from 4 different growers labelled as A, B, C, and D (the same growers as in experiment 1). The fruit was stored at 5 ${ }^{\circ} \mathrm{C}$ under CA conditions $\left(4 \% \mathrm{O}_{2}\right.$ and $\left.6 \% \mathrm{CO}_{2}\right)$ for 21 days. The fruit were forced to ripen with and without exogenous ethylene ( 0 or $100 \mathrm{ppm}$ ) from a cylinder containing concentrated gaseous ethylene. The ethylene was applied at $18{ }^{\circ} \mathrm{C}$ for $24 \mathrm{~h}$. After the ethylene exposure, the fruit was ripened at one of three different temperatures (15, 20 and $25^{\circ} \mathrm{C}$ ). Per condition, a total of 30 fruits were used, and RTE (days) was reached at a fruit firmness of 4.4-13.3 $\mathrm{N}$ for each individual fruit.

For all experiments each fruit was an experimental unit, and RTE was the response variable expressed as the number of days to reach a fruit firmness of 4.4-13.3 $\mathrm{N}$ for each fruit. Experiment 1 considered one factor (grower) with four levels (A, B, C and $\mathrm{D}$ ), and 115 replicates for each grower were used. Similarly, experiment 2 evaluated one factor (postharvest treatment) with three levels (RA, CA and control group), and 100 fruits per treatment were used. Finally, experiment 3 was 
a multifactorial experiment that considered three factors (growers and ripening conditions such as ethylene and temperature). In addition, the multifactorial experimental design was multileveled, i.e., four levels for growers (A, B, $\mathrm{C}$ and $\mathrm{D})$, two levels for ethylene concentration (0 and $100 \mathrm{ppm}$ ) and three levels for temperature (15, 20 and $25^{\circ} \mathrm{C}$ ). For each treatment, combinations of 30 replicates were used.

The factors evaluated in this research are reported sources of ripening heterogeneity (Hernández et al., 2016). Location, microclimate and temperature, among other pre-harvest factors, could be linked to ripening heterogeneity. Therefore, the evaluation of different avocado growers could reveal a difference in heterogeneity when compared statistically. Hernández et al. (2016) reported that postharvest treatments such as temperature, ethylene application and controlled atmosphere reduce ripening heterogeneity. Since those conditions correspond to commercial treatments used by the avocado industry, evaluating significant differences is appropriate.

\section{Residual computing and multiple comparisons}

Different authors have proposed analogous ways of computing the residual from the analysis of variance (ANOVA). The common criterion is to obtain residuals from the means or the median of treatments (Milliken and Johnson, 2009). The residuals from the ANOVA by the mean comparisons of the 3 different experiments were obtained directly by Statgraphics Centurion XVII software (StatPoint Technologies Inc., Rockville, Maryland, USA) and Excel 2010 (Microsoft Inc.). Two types of residuals were included in the analysis:

$e_{i j_{B F}}=\left|y_{i j}-\tilde{y}_{i}\right|$ non-parametric analysis proposed by Brown and Forsythe (1974)

$e_{i j_{F R}}=\left(y_{i j}-\bar{y}_{i}\right)$ parametric analysis proposed by Ferrer and Romero (1993) where $e_{i j}$ is the residual; $y_{i j}$ denotes the value of the response variable; $\bar{y}_{i}$. denotes the mean of the $\mathrm{j}^{\text {th }}$ treatment; and $\tilde{y}_{i}$. denotes the median of the $\mathrm{j}^{\text {th }}$ treatment.

To evaluate the effects of the different treatments on the response variability (dispersion effect), oneway and multifactorial ANOVA were performed on the squared residuals. In addition, multiple comparisons of squared residuals based on Fisher's least significant difference were performed.

\section{Statistical analysis}

The classical approach of a variance analysis through the Bartlett, Levene, Cochran and Hartley F-MAX tests were performed. Squared residuals were calculated with ANOVA, and multiple comparisons were performed in Statgraphics Centurion XVII.

\section{Results and discussion}

Classical statistical approach: Bartlett, Levene and Cochran followed by an F-MAX test

The statistical tests of variance homoscedasticity of Bartlett, Levene and Cochran applied to experiment 1 indicated significant differences $(\mathrm{P} \leq 0.05)$ among the variances of growers $\mathrm{A}$, $\mathrm{B}, \mathrm{C}$ and $\mathrm{D}$, and when applied to experiment 2 , differences were found between regular air and CA (Table 1). This test did not indicate which standard deviations were different. Thus, an F-MAX test was used as a post hoc test. For experiment 1 , the F-MAX test revealed that paired combinations of growers A-C and C-D were different $(\mathrm{P} \leq 0.05)$. For experiment 2 , all standard deviations were different among them $(\mathrm{P} \leq 0.05)$. In all cases, the response variable was the days to reach edible ripeness (RTE). Those previous statistical tests only provided information related to one standard deviation being different from the remainder but provided 
no information on the degree of heterogeneity. Thus, to complement that information, a graphical frequency or density histogram was generated (Figure 1). To rank the different treatments in terms of heterogeneity, two-by-two comparisons were performed. Thus, according to the Bartlett, Levene, and Cochran tests, followed by the F-MAX test and supported by the histograms, in experiment 1 , grower $\mathrm{C}$ was significantly more heterogeneous in RTE than A and D. Similarly, in experiment 2, the treatments can be ordered for RTE or more heterogeneity as follows: harvest $>$ RA $>$ CA. The data matrix of experiment 3 is much more complex to analyze because it incorporates three factors (grower, temperature and ethylene exposure) with different levels.

The results indicated significant differences among the growers (Table 1). The F-MAX test and histograms (Figure 2) revealed that grower A resulted in less heterogeneity than $\mathrm{B}$ and $\mathrm{C}$ and that $\mathrm{C}$ is more heterogeneous than $\mathrm{D}$. The evaluation of the interactions of the different factors through this approach is not possible given that the tests of Bartlett, Levene and Cochran allow the evaluation of only one factor at a time. Thus, all treatments were assembled as one factor; however, this arrangement does not allow the interaction evaluation but rather allows us to compare all of the possible significant

Table 1. Variance tests to compare different postharvest treatments applied to Hass avocado batches to evaluate postharvest ripening heterogeneity (RTE or days to reach edible ripeness)

\begin{tabular}{|c|c|c|c|}
\hline & $\begin{array}{c}\text { Bartlett } \\
\text { (P-value) }\end{array}$ & $\begin{array}{l}\text { Levene } \\
\text { (P-value) }\end{array}$ & $\begin{array}{r}\text { Cochran } \\
\text { (P-value) }\end{array}$ \\
\hline \multicolumn{4}{|l|}{ Experiment 1: } \\
\hline Grower $\mathrm{A}-\mathrm{B}-\mathrm{C}-\mathrm{D}$ & $0.0347 *$ & $0.0076^{*}$ & $0.0152 *$ \\
\hline \multicolumn{4}{|l|}{ Experiment 2: } \\
\hline Harvest - RA - CA & $0.0000 *$ & $0.0000 *$ & $0.0000^{*}$ \\
\hline \multicolumn{4}{|l|}{ Experiment 3: } \\
\hline Grower $\mathrm{A}-\mathrm{B}-\mathrm{C}-\mathrm{D}$ & $0.0021 *$ & 0.6339 & $0.0170^{*}$ \\
\hline Temperature $15-20-25^{\circ} \mathrm{C}$ & 0.0854 & 0.7618 & 0.2604 \\
\hline Ethylene $0-100 \mathrm{ppm}$ & 0.0433 & 0.4686 & 0.0433 \\
\hline All treatments & $0.0000 *$ & $0.0096^{*}$ & $0.0000^{*}$ \\
\hline
\end{tabular}

*A P-value $\leq 0.05$ within a row indicates significant differences on the standard deviations. Harvest: avocado fruit ripened at harvest at $20^{\circ} \mathrm{C}$; RA: cold storage in regular air $\left(5^{\circ} \mathrm{C}\right.$ for $\left.30 \mathrm{~d}\right)$; CA: controlled atmosphere $\left(4 \% \mathrm{O}_{2}\right.$ and $6 \% \mathrm{CO}_{2}$ at $5{ }^{\circ} \mathrm{C}$ for $30 \mathrm{~d}$ ) storage.
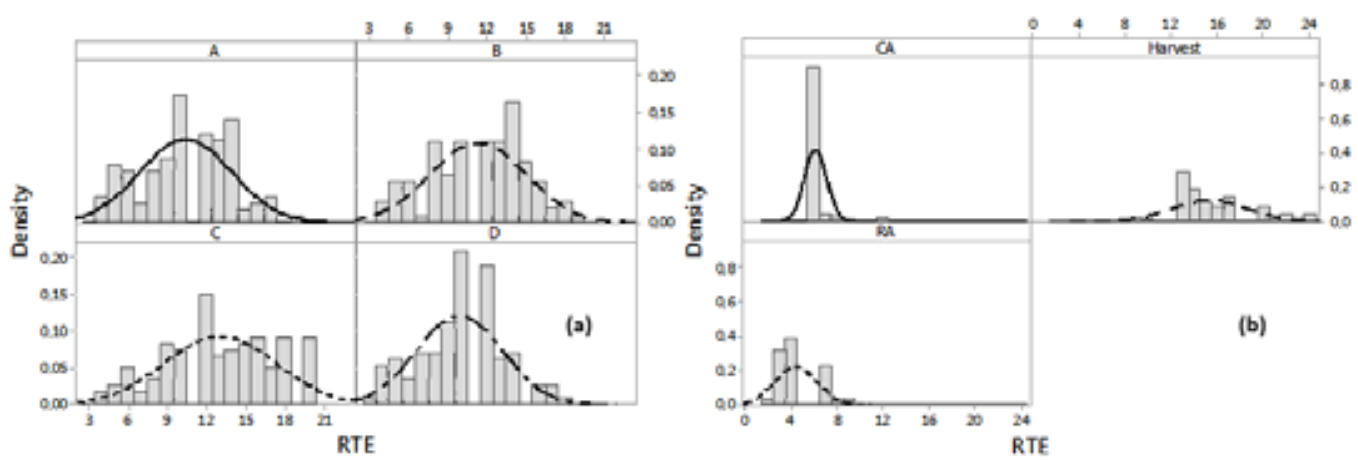

Figure 1. Histograms of number of days to reach edible ripeness of individual Hass avocados (RTE) (a) Experiment 1: growers (A-B-C-D); (b) Experiment 2: harvest, cold storage in regular air (RA) and controlled atmosphere (CA) storage. 
differences. This arrangement resulted in 24 treatments of 30 samples each. All of the statistical tests mentioned before resulted in significance $(\mathrm{P} \leq 0.05)$, but the paired evaluation with the F-MAX test resulted in 276 tests with high probabilities of obtaining a high type I error or false positives (Conover et al., 1981). If a comparison procedure based on a Bonferroni pairwise comparison is used, it can produce misleading results because it is conservative, particularly when the number of comparisons is very large because the comparison significance level can become too small to be of value (Mason et al., 2003).

\section{Multiple comparisons of squared residuals}

The $e_{i j}$ could be assumed similar to a parametric residual because it is computed from the mean of each treatment, as the mean is clearly affected by the extreme (outliers) values of $y_{i j}$. In fact, the outlier values could imply a departure from a normal distribution of the sample even when the distribution is symmetric (Shapiro and Wilks, 1965).

Otherwise, $e_{i j_{B F}}$ corresponds to a non-parametric residual because it is calculated from the median of each treatment. This residual is an estimator of the calculated standard deviations of the observations. Since it is computed from medians, it provides more powerful tests than when calculated from means when the data are not symmetrically distributed because the median is not affected by extreme sample values (Stephens, 1977; Milliken and Johnson, 2009).

The multiple comparisons test of squared residuals allows the homogeneity of several groups of samples to be determined statistically and graphically. The application of both methods (parametric and non-parametric) to experiment 1 resulted in significant differences between the squared residual of grower $\mathrm{C}$ with $\mathrm{A}, \mathrm{B}$ and $\mathrm{D}(\mathrm{P} \leq 0.05)$. In this case, there were no differences between the use of the mean or median for squared residual calculations because the sample distributions did not present significant outlier values and showed a symmetric shape. Previously, the methods of Bartlett, Levene and Cochran followed by an FMAX test resulted in grower $\mathrm{C}$ being significantly different than $\mathrm{A}$ and $\mathrm{D}$, missing the significant difference with grower B. Classical tests are very sensitive to normal and asymmetric distributions. In all grower histograms (Figure 1a), it can be observed that heavy tails remain on the right side of histograms mainly because, during the early season, some immature fruit could be harvested; this fruit will not ripen properly, and some will never reach edible ripeness (Magwaza and Tesfay, 2015). Therefore, the classical variance tests will not be suitable for early season heterogeneity ripening evaluation. In addition, the biological interpretation of this heterogeneity among the growers is attributed to different growing conditions and cultural practices.

In experiment 2, using the multiple comparisons of squared residuals $\left(e_{i j_{F R}}\right.$ and $\left.e_{i j_{B F}}\right)$ resulted in significant differences among the squared residuals of the different treatments with the control group (ripened at harvest) $(\mathrm{P} \leq 0.05)$. Treatments that included controlled atmosphere in combination with cold storage and cold storage in regular air conditions resulted in a reduction of the RTE heterogeneity compared with the samples at harvest. The physiological and biochemical interpretation still remains to be elucidated, but cold has been

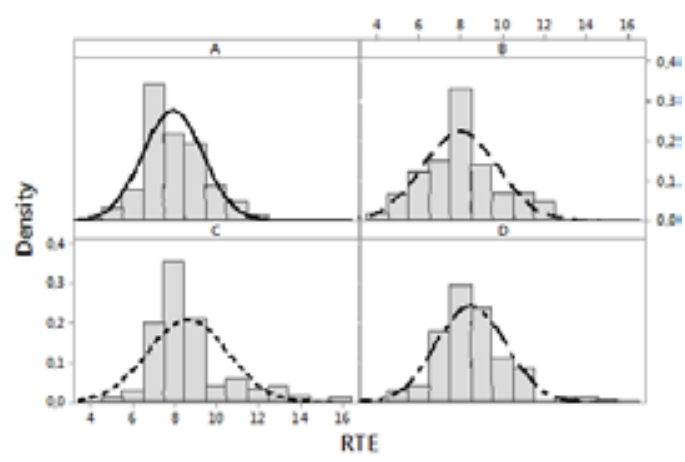

Figure 2. Histograms of number of days to reach edible ripeness of individual Hass avocados (RTE) (RTE) for growers (A, B, C and D) from experiment 3. 
previously reported to induce increased enzyme activity (Defilippi et al., 2015). The classical analysis showed that all treatments were different from each other. Similar to experiment 1, the heavy tails observed on the spread of days to reach edible ripeness (Figure 1b) would lead to a misunderstanding of the variance analysis using the classical methods. Furthermore, one of the disadvantages of the F-MAX test is the pair-by-pair comparisons that can result in an elevated number of false positives because it is very sensitive to non-normal distributions (Conover et al., 1981).

Finally, for the third experiment analyzed, we used a multifactorial ANOVA for comparing the three different factors (grower, temperature and ethylene). The multiple comparisons test of squared residuals displayed significant differences $(\mathrm{P} \leq 0.05)$ only for growers (Figure 3 ). The temperature and ethylene treatments were not significant, and neither were the interactions between all factors. The non-parametric method $\left(e_{i j_{F R}}\right)$ showed that grower A was significantly less heterogeneous than growers B and C. However, the parametric method $\left(e_{i j}\right)$ showed that grower A was less heterogeneous than all other growers $(\mathrm{P} \leq 0.05)$. Since grower $\mathrm{C}$ has a heavy tail on the right side (Figure 3), the Brown-Forsythe method as well as the modified Levene's test is more suitable because it uses the medians for computing the residual, providing a powerful test when data are not symmetrical and present heavy-tailed distributions (Levene, 1960;
Milliken and Johnson, 2009). Slightly similar results were observed with the Bartlett's and Cochran's tests where grower A was significantly less heterogeneous than growers $\mathrm{B}$ and $\mathrm{C}$, and C was more heterogeneous than D. Similar to experiment 2, the disadvantage of the F-MAX test is that the pair-by-pair comparisons can result in an elevated number of false positives. Nevertheless, these interpretations were generated from small designed experiments (30 fruits); we recommend that a higher number of samples $(n=100)$ be used for evaluating the heterogeneity of avocado ripening.

An objective statistical analysis for the evaluation of avocado ripening heterogeneity would be a useful tool for the industry, especially for making early decisions on classifying different fruits and batches based on their ripening patterns if the "ready-to-eat" market is the target. This statistical method would allow different batches of fruit to be objectively compared and early decisions to be made regarding the fate of avocado fruits, thus reducing logistical problems for marketers and fruit losses.

In conclusion, the complex physiology of Hass avocados as evidenced through heterogeneous ripening (e.g., wide variability in the number of days to reach edible ripeness) demands a solid statistical approach to compare treatments. Our results demonstrated that the multiple comparisons of squared residuals $\left(e_{i j}{ }_{B F}\right)$ using the nonparametric Brown and Forsythe method was the
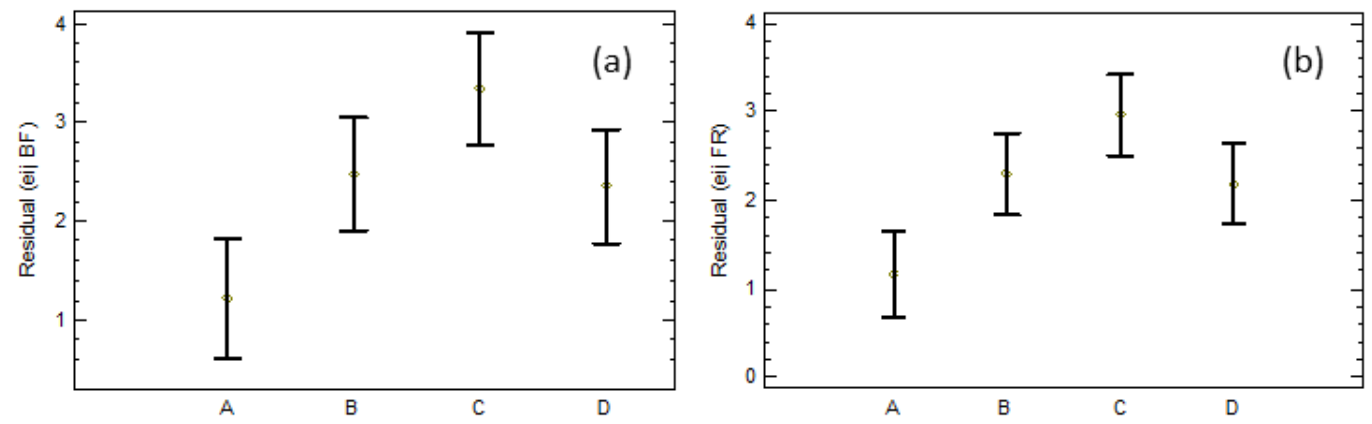

Figure 3. Multiple comparisons test of squared residuals for experiment 3 (growers). (a) Residuals from Brown and Forsythe $\left(e_{i j}{ }_{B F}\right)$ for growers A, B, C and D; and (b) residuals from Ferrer and Romero $\left(e_{i j}\right)$ for growers A, B, C and D. Dots represent the mean of squared residuals, and overlapping intervals are not statistically significant $(95 \%$ confidence). 
most suitable test of variance for analyzing this type of data. This simple method can be used to evaluate postharvest treatments with multifactorial ANOVA and graphical comparisons of standard deviations and allow the industry to make decisions based on a solid statistical approach.

\section{Acknowledgements}

R. Pedreschi thanks the Fondecyt de Iniciación 11140052 grant from CONICYT, Chile. C. Fuentealba thanks the post-doctoral grant of VRIEA of Pontificia Universidad Católica de Valparaíso (Chile).

\title{
Resumen
}

\begin{abstract}
C. Fuentealba, R. Pedreschi, I. Hernández y J. Saavedra. 2016. Enfoque estadístico para evaluar la heterogeneidad de paltas Hass, sometidas a diferentes estreses abióticos en postcosecha. Cien. Inv. Agr. 43(3):356-365. La palta Hass (Persea americana Mill.) es mundialmente comercializada y los países importadores demandan productos homogéneos y de calidad consistente. Sin embargo, debido a la compleja fisiología del fruto se observa una amplia variabilidad durante su maduración postcosecha, es decir, heterogeneidad en los días para alcanzar la madurez comercial. Por tal motivo, es necesario evaluar la eficacia de tratamientos postcosecha en la reducción de la heterogeneidad en la maduración a través de un método objetivo y simple. El objetivo de este estudio fue comparar diferentes métodos estadísticos para la evaluación de la heterogeneidad en la maduración. A los diferentes tratamientos se aplicaron pruebas de homogeneidad de varianza como Bartlett, Cochran, Levene. Además, se realizó una comparación múltiple a residuales cuadráticos (paramétricos y no paramétricos). Las pruebas estadísticas clásicas (Bartlett, Cochran y Levene) mostraron resultados similares a la comparación múltiple de residuos cuadráticos sólo cuando el tamaño de muestra es grande $(\mathrm{n}=100)$ y se realiza sólo un tratamiento. Todos los métodos estadísticos fueron capaces de detectar diferencias significativas en la heterogeneidad en la maduración entre productores y diferentes condiciones de almacenamiento. La comparación múltiple de residuos cuadráticos fue el método más adecuado para experimentos multifactoriales y de tamaños de muestras más pequeños $(n=30)$ en comparación con las pruebas clásicas, donde éstas últimas conducen a un aumento en la probabilidad de obtener falsos positivos o error tipo I.
\end{abstract}

Palabras claves: Comparación múltiple, desviación estándar, heterogeneidad, maduración, paltas.

\section{References}

Arpaia, M.L., and D. Obenland. 2012. Avocado Postharvest Biology: Determinants of Eating Quality. California Avocado Commission 2011-12 Production Research Report.

Bill, M., D. Sivakumar, A.K. Thompson, and L. Korsten. 2014. Avocado fruit quality management during the postharvest supply chain. Food Reviwes International 30:169-202.

Blakey, R.J., and J.P. Bower. 2007. The feasibility of a hot water treatment for South African avocados (Persea americana [Mill.] cv Hass).
South African Avocado Growers Association 30:66-68.

Blakey, R.J., J.P. Bower, and I. Bertling. 2009. Influence of water and ABA supply on the ripening pattern of avocado (Persea americana Mill.) fruit and the prediction of water content using Near Infrared Spectroscopy. Postharvest Biology and Technology 53:72-76.

Bower, J.P., and J.G. Cutting. 1988. Avocado fruit development and ripening physiology. Horticultural Reviews (Am. Soc. Hortic. Sci) 10:229-271.

Brown, M.B., and A.B. Forsythe. 1974. Robust tests for the equality of variances. Journal of 
the American Statistical Association 69:364367.

Carroll, R.J., and D. Ruppert. 1988. Transformation and Weighting in Regression, Chapman \& Hall/ CRC Monographs on Statistics \& Applied Probability. Taylor \& Francis.

Conover, W.J., M.E. Johnson, M.M. Johnson. 1981. A comparative study of tests for homogeneity of variances, with applications to the outer continental shelf bidding data. Technometrics 23:351-361.

Defilippi B., P. Robledo, S. Rivera, and R. Ferreyra. 2015. Heterogeneidad de la calidad y condición de paltas. In: Defilippi B., R. Ferreyra and S. Rivera (eds.). Optimización de la calidad de palta 'Hass'. Boletín INIA 307:43-68.

Ferrer, A.J., and R. Romero. 1993. Small samples estimation of dispersion effects from unreplicated data. Communications in Statistic - Simulation and Computation 22:975-995.

Hernández, I., C. Fuentealba, J.A. Olaeta, S. Lurie, B. Defilippi, R. Campos-Vargas, and R. Pedreschi. 2016. Factors associated with postharvest ripening heterogeneity of "Hass" avocados (Persea americana Mill). Fruits 71:259-268.

Hershkovitz, V., H. Friedman, E.E. Goldschmidt, O. Feygenberg, and E. Pesis. 2009. Induction of ethylene in avocado fruit in response to chilling stress on tree. Journal of Plant Physiology 166:1855-1862.

Hofman, P.J., B.A. Stubbings, M.F. Adkins, R.J. Corcoran, A. White, and A.B. Woolf. 2003. Low temperature conditioning before cold disinfestation improves "Hass" avocado fruit quality. Postharvest Biology and Technology 28:123-133.

Hofman, P.J., B.A. Stubbings, M.F. Adkins, G.F. Meiburg, and A.B. Woolf. 2002. Hot water treatments improve "Hass" avocado fruit quality after cold disinfestation. Postharvest Biology and Technology 24:183-192.

Kruger, F.J., and L.S. Magwaza. 2012. Does orchard soil moisture content at the time of harvest influence the post-storage ripening pattern of "Hass" avocado fruit? Soth African Avocado Growers Association 35:47-53.
Kruger, F.J., and G.O. Volschenk. 2011. Ripening patterns of South African export "Hass" avocado hold-back samples from commercial 1-methylcyclopropene (SmartFreshSM) applications. VIII World Avocado Congress.

Levene, H. 1960. Robust tests for equality of variances. p. 278-292. In: Olkin, I. (ed.). Contributions to probability and statistics, Stanford Studies in Mathematics and Statistics. Stanford University Press, Palo Alto, California.

Lewis, C.E. 1978. The maturity of avocados-a general review. Journal of the Science of Food and Agriculture 29:857-866.

Magwaza, L., and S. Tesfay. 2015. A Review of destructive and non-destructive methods for determining avocado fruit maturity. Food Bioprocess Technology 8:1995-2011.

Mason, R.L., R.F. Gunst, and J.L. Hess. 2003. Statistical Design and Analysis of Experiments: With Applications to Engineering and Science, Wiley Series in Probability and Statistics. Wiley.

Milliken, G.A., and D.E. Johnson. 2009. Analysis of Messy Data Volume 1: Designed Experiments, Second Edition, Analysis of Messy Data. CRC Press.

Montgomery, D.C. 2008. Design and Analysis of Experiments, Student solutions manual. John Wiley \& Sons.

Pedreschi, R., Muñoz, P., Robledo, P., Becerra, C., Defilippi. B.G., van Eekelen, H., Mumm, R., Westra, E., and De Vos, R.C.H. 2014. Metabolomics analysis of postharvest ripening heterogeneity of 'Hass' avocadoes. Postharvest Biology and Technology 92:172-179.

Rykov, V.V, . Balakrishnan, and M.S. Nikulin. 2010. Mathematical and Statistical Models and Methods in Reliability: Applications to Medicine, Finance, and Quality Control, Statistics for Industry and Technology. Birkhäuser Boston.

Shapiro, S., and M. Wilk. 1965. An analysis of variance test for normality (complete samples). Biometrika 52:591-611.

Stephens, M., 1977. Goodness of fit for the extreme value distribution. Biometrika 64, 583-588.

Woolf, A.B., and I.B. Ferguson. 2000. Postharvest responses to high fruit temperatures in 
the field. Postharvest Biology and Technology 21:7-20.

Woolf, A.B., Wexler, A., Prusky, D., Kobiler, E., Lurie, S., 2000. Direct sunlight influences postharvest temperature responses and ripening of five avocado cultivars. Journal of the American Society for Horticultural Science 125, 370-376.
Woolf, A.B., A. White, M. Arpaia, and K. Gross. 2004. Avocado. In: Gross, K., Wang, C., Salveit, M. (eds.). Agriculture Handbook 66: The storage of Fruits, Vegetables and Florist and Nursery Stocks. Available online at: http://www.ba.ars. usda.gov/hb66/avocado.pdf (Website accessed: September 10, 2015). 